\title{
AMCoR
}

Asahikawa Medical College Repository http://amcor. asahikawa-med. ac. jp/

JOURNAL OF ARTHROPLASTY (2003) 18(2):134-139.

Acetabular components without bulk bone graft in revision surgery: A 5to 13-year follow-up study

Ito, H; Matsuno, T; Aoki, Y; Minami, A 


\section{Porous-Coated Cementless A cetabular Components Without Bulk Bone Graft in Revision Surgery}

: A 5- to 13-Year Follow-up Study

Hiroshi Ito, MD*; Takeo Matsuno, MD*; Yoshimitsu Aoki. MD†;

and Akio Minami, MD†

Asahikawa M edical College, J apan

*Department of Orthopaedics, Asahikawa Medical College

Midorigaoka Higashi 2-1-1-1, Asahikawa 078-8510, Japan

$\dagger$ Department of Orthopaedic Surgery, Hokkaido University, School of Medicine, Kita-ku Kita-15 Nishi-7, Sapporo 060-8638, Japan

Corresponding Author: Hiroshi Ito

Department of Orthopaedics, Asahikawa Medical College

Midorigaoka Higashi 2-1-1-1, Asahikawa 078-8510, Japan

Phone \#81-166-68-2511

FAX \#81-166-68-2519

E-mail: itobiro@asahikawa-med.ac.jp 


\section{Abstract}

Eighty-three consecutive revisions in 74 patients using a porous-coated acetabular component without bulk bone graft were followed at an average of 9.3 years (range, 5-13 years). A large-diameter cup was implanted in hips with adequate osseous support, and a high hip center technique using a standard- or smaller-diameter cup was selected in hips without sufficient bone stock. Acetabular bone deficiency was segmental in 18 hips, cavitary in 30, and combined segmental and cavitary in 35 . Four (5\%) cups were revised again; 1 for infection, 1 for dislodgement of the polyethylene liner from the metal shell, and 2 for recurrent dislocation. There was no acetabular component categorized as definitely loose at final follow-up. The current satisfactory results encourage the use of this simple technique.

Key words : porous-coated cementless acetabular component, revision surgery

\section{Introduction}

Acetabular bone defect is a major problem in revision surgery. The current main acetabular reconstruction techniques include placement of an acetabular component in combination with structural bone graft, placement of a large acetabular component, and placement of an acetabular component on host bone in a superior position (a high hip center). Massive bulk bone grafts in the weight bearing area were previously applied without metallic support ring or cage for acetabular reconstruction, however, the results were discouraging $[1,2]$. Several excellent intermediate-term results in association with the use 
of a porous-coated cementless socket for acetabular revision have been reported, even in the presence of acetabular bone loss [3-15]. Large or extra-large sockets provide several advantages over standard-sized implants $[4,15]$. The surface contact area between the porous-coated component and host bone, over which forces are dissipated, is maximized. Large cups fill many bone defects which reduce the need for the amount of bone grafting. Large sockets tend to normalize the center of hip rotation, which may restore soft-tissue tension and reduce impingement between the femur and the pelvis. In the present study, a large-diameter cup was preferred in hips with adequate osseous support. In hips without sufficient bone stock including destroyed superior osseous support, however, a high hip center technique using a standard- or smaller-diameter cup was indicated [3].

We have consecutively used a porous-coated cup without structural bulk bone graft in revision surgery since 1989 to avoid problems associated with progressive collapse of the grafted bone. The current study evaluated intermediate-term results of acetabular reconstruction without bulk bone graft in consecutive revisions performed by one experienced surgeon.

\section{Materials and Methods}

Between January 1989 and December 1996, 103 consecutive revisions using a porous-coated acetabular component were performed by one senior author (T.M.) in patients who were followed prospectively. Nine patients (9 hips) died of causes unrelated to the revision surgery before the minimum 
follow-up of 5 years. Seven patients ( 7 hips) were bedridden and too ill to return for the latest follow-up evaluation of this study. Four patients (4 hips) were lost to follow-up. All these 20 revisions of the acetabular component were well-fixed without evidence of osteolysis and none of the hips had required reoperation at the time of the latest follow-up examination, at an average of 28 months (range, 12 to 46 months) postoperatively. The remaining 83 hips in 74 patients, including 9 patients who had had a bilateral revision, were available for clinical and radiographical review after a minimum follow-up of 5 years. During the study period, there was no other technique used for acetabular revision; therefore, we are reporting a prospective, consecutive series.

Sixty-nine hips had revision of both the femoral and acetabular component, and 14 hips had isolated acetabular revision. A cemented acetabular component was revised in 53 hips, a bipolar prosthesis in 22, a cementless acetabular component in 2 , unipolar hemiprosthesis in 5 , a cup arthroplasty in 1. Six of 83 hips had developed chronic infection, and the acetabular component was inserted 2 to 15 months after removal of the component.

The average duration of follow-up was 9.3 years (range, 5-13 years). Twenty-nine patients were men, and 45 patients were women. The average age at the time of the index operation was 59 years (range, 24-90 years). The average height was $154 \mathrm{~cm}$ (range, 138-178 cm), and average weight was 57 $\mathrm{kg}$ (range, 40-88 kg). The initial diagnosis was dislocated or subluxated 
osteoarthrosis in 43 hips, osteonecrosis in 19, fracture of the femoral neck in 12, rheumatoid arthritis in 5, ankylosing spondylitis in 2, pathological fracture of solitary bone cyst in 1, and slipped capital femoral epiphysis in 1 .

The indication for revision was painful aseptic loosening in 74 hips, reimplantation after removal of the component due to infection in 6 , fracture of a bipolar polyethylene liner in 2, and recurrent dislocation in 1 .

Pre-revision acetabular bone deficiencies were classified retrospectively. According to the system of the American Academy of Orthopaedic Surgeons, the deficiency was categorized as segmental in 18 hips, as cavitary in 30 , as combined segmental and cavitary in 35 , and pelvic discontinuity in none [16].

All of the procedures were performed through the posterolateral approach without trochanteric osteotomy. Each acetabular component was individually assessed. The acetabular reconstruction technique was consecutively uniform as described by Dearborn and Harris [3]. The size of the acetabular component was preoperatively planned and the acetabular bone loss was evaluated intraoperatively. The method for the reconstruction was selected. If there was adequate osseous support to allow placement of a large-diameter acetabular component with resulting hip center close to the normal level, this technique was preferred. As we preferred at least 50\% contact of the acetabular component with host bone, if there was not sufficient bone stock for the use of a large component, an approach resulted in a high hip center, generally using a standard or smaller component placed in the superior 
position of the acetabular cavity. This high hip center technique was performed in hips with severely destroyed superior osseous support, often with the absence of medial wall and anterior or posterior column. Leg-length discrepancy was corrected using a long-neck or calcar replacement type femoral component when the high hip center technique was utilized. To avoid impingement, ischium and greater trochanter was removed in some patients.

The acetabular bed was prepared with hemispherical reamers in the so-called line-to-line fashion; that is, the nominal outer diameter of the acetabular component was equal to the nominal outer diameter of the last reamer that was used. Fifty-nine Harris-Galante Porous (HGP; Zimmer, Warsaw, Indiana) cups, 13 Omnifit (Howmedica Osteonics, Allendale, New Jersey), 7 S-ROM (DePuy Johnson \& Johnson, Warsaw, Indiana) cups, and 4 Richards Modular Hip (Smith and Nephew, Memphis, Tennessee) cups were used for the respective femoral revisions. These types of cups have multiple screw-holes in the shell, which were used for screw fixation in all hips. Structural bulk bone graft was not performed in any hip. Only non-structural autogenous paste bone graft retrieved from the hemispherical acetabular reamer was used in 23 hips and a combination of autogenous paste bone graft and morseled fresh-frozen allograft was used in 3 hips. Non-structural bone graft was packed into the acetabular defect and was shaped into a hemisphere with the acetabular reamer in the reverse mode. An average of 4.6 screws (range, 2-7 screws) were used for fixation. An average outer diameter of the acetabular component was $56.3 \mathrm{~mm}$ (range, 42-71 mm). All components 
were considered rigidly fixed at the time of revision surgery.

Clinical evaluations were made according to the Harris hip scoring system [17]. Hips with a score of 90 to 100 points were defined as having an excellent result, 80 to 89 points as a good result, 70 to 79 points as a fair result, and less than 70 points as a poor result. Orthopaedic surgeons who had not performed the surgery evaluated the patients. An anteroposterior radiograph and true lateral radiograph were made preoperatively and at each follow-up examination. Preoperative, immediate postoperative, and all intermediate radiographs as well as those made at the most recent follow-up were analyzed by orthopaedic surgeons who specialized in hip surgery, other than the operating surgeon.

A hip center was defined as high in hips with a center of rotation of the femoral head located $\geq 35 \mathrm{~mm}$ proximal to the interteardrop line [3], and as anatomic in those $<35 \mathrm{~mm}$ proximal to that. Definite acetabular loosening was defined as acetabular migration of $\geq 2 \mathrm{~mm}$ in either the horizontal or vertical direction, rotation of the implant, screw breakage, or a radiolucent line of $>1 \mathrm{~mm}$ in all zones [18]. Migration of the acetabular component and the preoperative and postoperative centers of hip rotation were estimated by measuring the position of the implant with respect to the interteardrop line and the tear drop on immediate postoperative and subsequent radiographs [19]. Radiolucent lines at the prosthesis-bone interface were recorded using the three zones described by DeLee and Charnley [20]. Stability of the femoral component was assessed according to the method of Engh et al for uncemented 
implants and according to the method of Harris et al for cemented implants $[21,22]$.

A Kaplan-Meier survivorship analysis was performed to assess the life span of the hybrid total hip arthroplasty in which the end point was defined as revision surgery.

\section{Results}

Hip Center

Before revision the hip center was a mean of $35 \mathrm{~mm}$ (range, 10-58 $\mathrm{mm}$ ) proximal to the interteardrop line, and after revision it was a mean of 32 $\mathrm{mm}$ (range, 12-55 $\mathrm{mm}$ ) proximal to the interteardrop line. Twenty-eight acetabular components were placed in the high hip center position with a mean of $38 \mathrm{~mm}$ (range, $35-55 \mathrm{~mm}$ ), and the other 55 acetabular components were placed in the anatomic position with a mean of $29 \mathrm{~mm}$ (range, 12-34 $\mathrm{mm}$ ) proximal to the interteardrop line. An average outer diameter of the acetabular component was $51.0 \mathrm{~mm}$ (range, 42-64 mm) in 28 hips with a high hip center, and $59.0 \mathrm{~mm}$ (range, 46-71 $\mathrm{mm}$ ) in 55 hips with an anatomic hip center. Before revision the center of hip rotation was a mean $33 \mathrm{~mm}$ lateral to the medial aspect of the teardrop, and after revision it was a mean of $37 \mathrm{~mm}$ lateral to the same landmark.

\section{Repeat Revisions}

Four (5\%) of 83 acetabular components were removed or revised again. The indications for removal or repeat revision were infection in 1 patient, 
dislodgement of the polyethylene liner from the metal shell in 1 patient, and recurrent dislocation in 2 patients. Late hematogenous infection necessitated removal of the acetabular component in 1 patient at 80 months postoperatively. Dislodgement of the polyethylene liner from the shell occurred because of tine breakage in the HGP-II component in 1 patient 86 months postoperatively. Two revisions were performed for recurrent dislocation 12 and 22 months postoperatively. The acetabular component was well fixed in these 3 patients except for 1 patient with infection. There were no acetabular components revised because of aseptic loosening. Another patient underwent revision of the femoral component because of aseptic loosening 84 months after surgery with retention of the acetabular shell and exchange of the polyethylene liner.

\section{Clinical Results}

The Harris hip score increased from a preoperative average of 54 points (range, $34-78$ points), to 81 points (range, 46-100 points) at the most recent follow-up for patients who did not have a subsequent revision. The result was excellent in 46 hips, good in 15, fair in 11, and poor in 7. Overall, $61(77 \%)$ of 79 hips showed excellent or good results (Fig. 1) and 18 (23\%) hips had fair or poor results. Before the index revision, $65(78 \%)$ of the original 83 hips had moderate or severe pain. At the time of the last follow-up, $40(51 \%)$ of the remaining 79 hips were not painful, $34(43 \%)$ were mildly painful, and $5(6 \%)$ were moderately painful. None of the hips was severely painful. 
Eighty-two of 83 hips excluding 1 hip in which the acetabular component was removed due to infection were assessed. The acetabular implant was categorized as stable in $70(85 \%)$ of these 82 hips, and in the other $12(15 \%)$ hips, the implant had a complete radiolucent line $<1 \mathrm{~mm}$ in width at the bone-implant interface but there was no evidence of migration, position change, or screw breakage. There was no acetabular component categorized as definitely loose. Eight (10\%) hips had a thin, non-progressive radiolucent line in zone III, $6(7 \%)$ in zone I, and $5(6 \%)$ in zone II. None of the hips had a continuous radiolucent line $>1 \mathrm{~mm}$ wide. There were no broken screws nor separation of the mesh from the shell. One hip demonstrated progressive osteolysis in zone I at 76 months postoperatively, which was $3 \mathrm{~mm}$ in diameter at the latest follow-up examination. There was no radiographic evidence of resorption of non-structural bone grafts between earlier and long-term follow-up examinations.

The Kaplan-Meier survivorship curve for removal of the acetabular component revealed a $94.6 \%$ chance of survival at 10 years $(95 \%$ confidence interval, $87 \%-100 \%)$.

\section{Complications}

The most frequent postoperative complication was dislocation, which occurred in $12(14 \%)$ hips. Dislocation occurred in 5 of 28 hips with the high hip center and in 7 of 55 hips with the anatomic hip center, which was not statistically significant (Fisher's exact test, $\mathrm{p}=.374$ ). Two of these hips underwent repeat revision of the acetabular component combined with 
exchange of the prosthetic femoral head. The remaining dislocations were treated without reoperation. Deep infection necessitated removal of the acetabular and femoral components in 1 patient as described. Reimplantation of both components was performed 4 months after removal, which was successful without recurrence of infection 36 months after surgery. There was no nerve palsy, or any other significant complications such as pulmonary embolism.

\section{Discussion}

This study evaluated the results of one specific technique in revision surgery; use of a porous-coated cementless acetabular component fixed with screws without structural bulk bone graft. The first rationale of this technique is that cementless hemispherical cups fixed with screws provide the best 10 -year results in acetabular reconstruction of any technique available $[3,7]$. While bulk autografts and allografts serve well over the early period, they demonstrate increasing failure rates with time $[1,2]$. Jasty and Harris reported that $12(32 \%)$ of 38 acetabular components with structural femoral head allograft became loose at a mean follow-up of 5.9 years [1]. Therefore, we have not performed structural bone grafting consecutively in revision acetabular reconstruction since 1989. Our principles have been use of a porous-coated cementless component as large as possible fixed with screws without structural bulk bone graft. If the acetabulum was dysplastic or superior bone defect of the acetabulum was extensive, we inserted a normal or 
smaller component in a high position [3]. As in other series using cementless cups inserted in revision surgery [3-15], the current porous-coated cups performed well and had a low failure rate. Moskal et al reported that 30 (94\%) of 32 uncemented revision cups remained stable after 3 to 9 years of follow-up [10]. Lachiewicz and Poon reviewed 57 cementless revision cups and found that none had loosened after a mean follow-up of 7 years [9]. Silverton et al reviewed 115 cementless revision sockets and found that none had been revised for loosening and 1 was radiographically loose after 7 to 11 years of follow-up [13]. These studies included acetabular reconstructions with bulk bone graft, and one strength of the current study is that a porous-coated acetabular component had been consecutively inserted without structural bulk bone graft.

Several studies demonstrated good results using large cementless cups in revision surgery $[4,7,15]$. Jasty reviewed 19 hips at a mean of 10 years after the implantation of a "jumbo cup" and reported only 1 failure, which occurred in a patient with pelvic discontinuity [7]. Whaley et al recently reported that the extra-large cementless acetabular component can provide durable implant fixation even in the presence of substantial bone loss at an average follow-up of 7 years [15]. These studies discussed several advantages of large cementless sockets; the technique of reaming to a larger hemisphere is straightforward but not complicated, acetabular bone defects are filled by the component itself obviating the need for extensive bone-grafting, the contact area between the cup and host bone can be increased as large as possible, and 
the hip center is translated to a more inferior and lateral location. The disadvantages are that large sockets limit bone stock restoration, and large or oblong bone defects cannot be filled in an inferior-to-superior direction without marked reaming of the anterior or posterior column or superior placement of the cup. Whaley et al defined an extra-large implant as one with a diameter at least $10 \mathrm{~mm}$ larger than the mean diameter of an implant of the same design that had been inserted during primary surgery [15]. Their definition of an extra-large socket was, therefore, $66 \mathrm{~mm}$ for men and $62 \mathrm{~mm}$ for women. The definition of "extra-large" may likely be different among patients with different pelvic and hip joint sizes. If an extra-large implant is defined as at least 10 mm larger than the mean diameter of implants that had been inserted during primary surgery, the mean diameter of implants in our dysplastic patients was $50 \mathrm{~mm}$. Therefore, the minimum diameter of an "extra-large" implant was 60 mm. Relative amount of bone defects in patients with smaller or dysplastic hip might differ from those described by Whaley et al. We suppose "extra-large" or "large" should indicate the relative ratio of the component size to the pelvis and hip joint, therefore we simply defined it "large" in this study.

If superior bone defect was extensive and bulk bone graft for the superior weight-bearing portion was necessary for coverage of the large socket, we inserted a smaller socket at a high position. Dearborn and Harris reported that $4(10 \%)$ of 40 cementless cups using a high hip center technique were removed; 3 for infection and 1 for aseptic loosening, and that 35 (97\%) of the remaining 36 cups were stable after a mean follow-up of 10 years [3]. They 
discussed that a high hip center did not adversely affect function of the abductor muscles, and recommended use of this technique.

The present high success rate encourages the use of this technique, however, if pelvic discontinuity is found across the anterior and posterior columns with total separation of the superior from the inferior acetabulum, other reconstruction techniques should be considered. Such techniques include the use of massive bulk graft with or without special reinforcement devices $[23,24]$. We have not used particulate bone grafts in association with a cemented socket [25], insertion of an antiprotrusio cage [26], or cementless elliptical acetabular components [27]. We are unable to compare our experience with those types of procedures. However, good results associated with porous-coated cementless sockets without bulk bone graft have encouraged us to use this simple technique for patients with moderate or marked bone loss without pelvic discontinuity.

\section{Figure Legends}

Fig. 1. Preoperative and follow-up radiographs of the hip in a 49-year-old woman.

(A) Preoperative radiograph showed the status of aseptic loosening of the acetabular component.

(B) Postoperative radiograph taken at 9-year follow-up examination showed that the 60-mm diameter Omnifit cup was stable. The patient had a good clinical result. 


\section{References}

1. Jasty M, Harris WH: Salvage total hip acetabular reconstruction in patients with major acetabular bone deficiency using structural femoral head allograft. J Bone Joint Surg Br 72:63, 1990

2. Kwong LM, Jasty M, Harris WH: High failure of bulk femoral head allograft in total hip acetabular reconstructions at 10 years. J Arthroplasty 9:33, 1994

3. Dearborn JT, Harris WH: High placement of an acetabular component inserted without cement in a revision total hip arthroplasty: results after a mean of ten years. J Bone Joint Surg Am 81:469, 1999

4. Emerson RH Jr, Head WC: Dealing with the deficient acetabulum in revision total hip arthroplasty: the importance of implant migration and use of the jumbo cup. Semin Arthroplasty 4:2, 1993

5. Garcia-Cimbrelo E: Porous-coated cementless acetabular cups in revision surgery: a 6- to 11-year follow-up study. J Arthroplasty 14:397, 1999

6. Harris WH, Krushell RJ, Galante JO: Results of cementless revisions of total hip arthroplasties using the Harris-Galante prosthesis. Clin Orthop $235: 120,1988$

7. Jasty M: Jumbo cups and morselized graft. Orthop Clin North Am 29:249, 1998

8. Lachiewicz PF, Hussamy OD: Revision of the acetabulum without cement with use of the Harris-Galante porous-coated implant: two to eight-year results. J Bone Joint Surg Am 76:1834, 1994 
9. Lachiewicz PF, Poon ED: Revision of a total hip arthroplasty with a Harris-Galante porous-coated acetabular component inserted without cement: a follow-up note on the results at five to twelve years. J Bone Joint Surg Am $80: 980,1998$

10. Moskal JT, Danisa OA, Shaffrey CI: Isolated revision acetabuloplasty using a porous-coated cementless acetabular component without removal of a well-fixed femoral component: a 3- to 9-year follow-up study. J Arthroplasty $12: 719,1997$

11. Padgett DE, Kull L, Rosenberg A, Sumner DR, Galante JO: Revision of the acetabular component without cement after total hip arthroplasty: three to six-year follow-up. J Bone Joint Surg Am 75:663, 1993

12. Paprosky WG, Perona PG, Lawrence JM: Acetabular defect classification and surgical reconstruction in revision arthroplasty: a 6-year follow-up evaluation. J Arthroplasty 9:33, 1994

13. Silverton CD, Rosenberg AG, Sheinkop MB, Kull LR, Galante JO: Revision of the acetabular component without cement after total hip arthroplasty: a follow-up note regarding results at seven to eleven years. J Bone Joint Surg Am 78:1366, 1996

14. Silverton CD, Rosenberg AG, Sheinkop MB, Kull LR, Galante JO: Revision total hip arthroplasty using a cementless acetabular component: technique and results. Clin Orthop 319:201, 1995

15. Whaley AL, Berry DJ, Harmsen WS: Extra-large uncemented hemispherical acetabular components for revision total hip arthroplasty. J Bone 
Joint Surg Am 83:1352, 2001

16. D'Antonio JA, Capello WN, Borden LS: Classification and management of acetabular abnormalities in total hip arthroplasty. Clin Orthop 243:126, 1989

17. Harris WH. Traumatic arthritis of the hip after dislocation and acetabular fracture: treatment by mold arthroplasty. J Bone Joint Surg Am 51:737, 1969

18. Massin P, Schmidt L, Engh CA: Evaluation of cementless acetabular component migration: an experimental study. J Arthroplasty 4:245, 1989

19. Martell JM, Pierson RH 3rd, Jacobs JJ, Rosenberg AG, Maley M, Galante GO: Primary total hip reconstruction with a titanium fiber-coated prosthesis inserted without cement. J Bone Joint Surg Am 75:554, 1993

20. DeLee JG, Charnley J: Radiographical demarcation of cemented sockets in total hip replacement. Clin Orthop 121:20, 1976

21. Engh CA, Bobyn JD, Glassman AH: Porous-coated hip replacement: the factors governing bone ingrowth, stem stress shielding, and clinical results. J Bone Joint Surg Br 69:45, 1987

22. Harris WH, McCarthy JC Jr, O'Neill DA: Femoral component loosening using contemporary techniques of femoral cement fixation. J Bone Joint Surg Am 64:1063, 1982

23. Garbuz D, Morsi E, Gross AE: Revision of the acetabular component of a total hip arthroplasty with a massive structural allograft: study with a minimum five-year follow-up. J Bone Joint Surg Am 78:693, 1996

24. Kerboull M, Hamadouche M, Kerboull L: The Kerboull acetabular reinforcement device in major acetabular reconstructions. Clin Orthop 378:155, 
25. Slooff TJ, Buma P, Schreurs BW, Schimmel JW, Huiskes R, Gardeniers J: Acetabular and femoral reconstruction with impacted graft and cement. Clin Orthop 324:108, 1996

26. Gill TJ, Sledge JB, Mller ME: The Burch-Schneider anti-protrusio cages in revision total hip arthroplasty: indications, principles and long-term results. J Bone Joint Surg Br 80:946, 1998

27. Berry DJ, Sutherland CJ, Trousdale RT, et al: Bilobed oblong porous coated acetabular components in revision total hip arthroplasty. Clin Orthop 371:154, 2000 